\title{
Achieving High Functioning Teams Using Team Based Learning in Flipped Classrooms
}

\section{Dr. Jennifer Mott, California Polytechnic State University}

Jennifer Mott is faculty in Mechanical Engineering at Cal Poly San Luis Obispo. Her research interests include using Team Based Learning in engineering courses and first year engineering programs.

\section{Dr. Steffen Peuker, California Polytechnic State University}

Dr. Steffen Peuker holds the James L. Bartlett, Jr. Assistant Professor position in the Mechanical Engineering Department at the California State University in San Luis Obispo. He is teaching courses, including laboratories, in the HVAC concentration and mechanical engineering including first-year courses. Dr. Peuker's educational research focuses on increasing student retention and success in engineering through implementation of a student success focused approach in introduction to engineering courses. In addition, his work in engineering education focuses on collaborative learning, student-industry cooperation, and developing innovative ways of merging engineering fundamentals and engineering in practice and research. He can be reached at speuker@ calpoly.edu. 


\title{
Achieving High Functioning Teams Using Team-Based Learning in Flipped Classrooms
}

\begin{abstract}
Achieving high functioning teams is essential for successfully implementing flipped classrooms methods relying on collaborative learning. Team-Based Learning is a unique approach to flipping a classroom because of its prescribed framework. This paper provides quantitative and qualitative data showing that teams are high functioning and high performing yet minimal instructor guidance and intervention is required when Team-Based Learning is used in mechanical engineering courses.

Introduction

From lab to design courses to group projects in general education or major courses, students are gaining experience working in teams. Unfortunately, teams may have one or more students doing all the work while another student does little to no work, yet reaps the benefits, i.e., grade, of the team. Active learning pedagogies using teams in the classroom, such as collaborative learning, Problem Based Learning or Team-Based Learning (TBL), need to incorporate classroom and grading policies that diminish the effect of students who wish to "slide by" on the knowledge and effort of hard working students. Instructors are also faced with how to set up teams and ensure students experience an improved learning environment. The purpose of this paper is to show that teams can be high functioning and high performing, yet have minimal instructor guidance and intervention when Team-Based Learning is used.

Team-Based Learning is currently used successfully nationally and internationally in professional schools such as medical, pharmacy, law, and business schools, and is gaining a foot hold in undergraduate programs in the humanities, sciences, and engineering ${ }^{1}$. TBL has been shown to improve the communication, team working, problem solving, critical thinking, and lifelong learning skills of students in TBL taught courses more than in traditionally taught courses $^{1,2}$. The nature of TBL—-such that the students solve problems in teams during class time, and then must report and defend their answers to the entire class-effectively gives students the opportunity to learn, practice and refine their communication, problem solving, critical thinking and team skills. Since these skills are critical to being successful in industry, it is our job to give students ample opportunity to develop these skills in their engineering student career, and using TBL as a teaching/learning technique in engineering courses is one option.
\end{abstract}

Another benefit for the students is in-depth knowledge and understanding of topics that comes from solving complex problems. Students gain an appreciation for team work and learn to work as an effective team mate. The effectiveness of team work can also be demonstrated to the students-Michaelsen et al. ${ }^{2}$, has shown that in the past twenty years, over $99.95 \%$ of the teams have outperformed their best member by an average of almost $14 \%$, and the worst team typically outperforms the best student in class. 
Benefits for instructors and administrators include: (1) minimal team facilitation because the groups tend to develop into self-managed learning teams. (2) TBL is cost effective since it can be used in large classes using the same instructor/TA costs as small classes. (3) There are fewer worries about students not being in class or failing to prepare for class. (4) Student-faculty interactions are more like working with colleagues when students are prepared for class and instructors have time to develop personally rewarding relationships with students ${ }^{2}$.

\section{Description of Team-Based Learning}

Team-Based Learning (TBL) is a specific pedagogical tool that emphasizes collaborative learning and is distinct from other cooperative or collaborative pedagogies because it follows a prescribed sequence of individual work and group work, and includes immediate feedback as well as peer evaluation. TBL is similar to other flipped classroom approaches in the sense that students have to prepare, e.g. by reading a chapter of a textbook, before coming to class to be prepared for in-class discussions and activities. The uniqueness of TBL is that in class students work in permanent teams throughout the quarter, activities follow a prescribed process-first a reading assignment (or study material from other sources), then an in-class quiz, and finally problems solved interactively in class that require students to apply facts and concepts from the pre-reading.

The framework of assuring that students come prepared to class is called the "Readiness Assurance Process" (RAP), which is unique to TBL. The RAP consists of an individual Readiness Assurance Test (iRAT) and a team Readiness Assurance Test (tRAT). Students first take the iRAT as an individual, and then take the tRAT, answering the same multiple choice questions from the iRAT as a team. During the tRAT, each team must come to a consensus for the answers to the questions, and they immediately check their answers using the Immediate Feedback Assessment Technique (IF-AT) form. The IF-AT form-shown in Figure 1-is a scratch off sheet in which a star is located under the correct answer. Teams receive points based on the number of scratches it takes to determine the correct answer. Using the IF-AT form during the tRAT is key to help students correct misconceptions in real time, and the points-scale gives the students motivation to learn to work together effectively as a team without direct instructor input. After all teams have completed the tRAT, the instructor can give a short-typically 5 to 10 minute-lecture clearing up any remaining confusion about the topic. Students are given an opportunity to submit a written appeal, as a team, of any RAT question they believe to be ambiguous.

The applications-on which the most time is spent in class-are problems that the students must solve as a team. The applications follow a 4-S format: Same problem, Significant problem, Specific choice, and Simultaneous report. A class discussion accompanies each application, and mini-lectures are given throughout to clarify misconceptions and answer questions. The problems are related to the course content and are challenging and rich enough that one student alone could not solve the problem in the time given, requiring the students to work together if they want to be successful in answering the problem. 


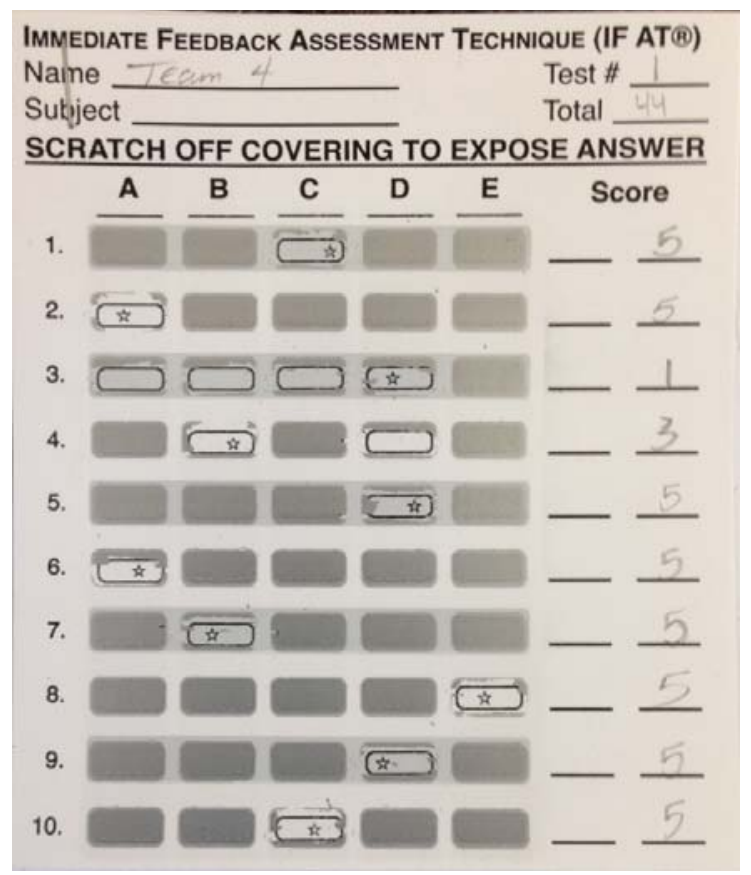

Figure 1: IF-AT Form. Points are given based on the number of scratches it takes to determine the correct answer.

Creating student teams is crucial for successful implementation of TBL. Teams in TBL consist of 5-7 students and are permanent for the whole term. The larger size of teams allows for more complex problems to be assigned to the teams. Teams should be balanced and diverse-meaning the teams should consist of student with ranges of skills, opinions, personal experiences etc.-in order that each team has a wide range of intellectual power available. There are several methods that can be used to form teams in TBL, and for more details see Sibley ${ }^{3}$. For this study, the Team-Maker system, "a web-based software tool that surveys students about criteria that instructors want to use when creating teams and uses a max-min heuristic to determine team assignments based on distribution criteria specified by the instructor" ${ }^{4}$, was used to assign students to teams.

Another essential part of TBL is peer review. Students rate their team mates on their contributions to the team performance and the peer evaluation is part of the final grade. The Comprehensive Assessment of Team-Member Effectiveness (CATME) peer evaluation instrument has been used for the student peer evaluations for this study ${ }^{5,6}$. Peer evaluation is completed by the teams twice per term. The first evaluation is at the end of week three, and used as a formative peer evaluation-it is not graded but is used by the students as feedback to improve. The second peer review is completed at the end of the term and is used as an adjustment to the personal team grades. Adjustment scores are out of 1.0 and are used as a multiplication factor to determine the final team grade of a student. Scores typically will range from a high of 1.05 for the outstanding team members and to a low of 0.96 for team members who are not as good. Students who have adjustments factors lower than 0.96 are those who miss class often and do not come prepared.

In summary, the uniqueness of the TBL framework is that students are held accountable for both their individual work — iRAT, peer evaluations — and group work — tRAT, and applications. The 
majority of class time is used for interactive team assignments that use the course content applied to larger and more difficult problems than can normally be done by individual students. For additional details about TBL and how to implement it in the class room see Sibley ${ }^{3}$.

Methods

Overall 173 students in 32 teams have participated in TBL taught mechanical engineering courses in the thermal sciences. The courses include two fundamental courses-Thermodynamics I and Heat Transfer-and two technical electives-Fundamentals of HVAC Systems, and Introduction to Refrigeration Principles.

To assess the success of using Team Based Learning, the Team Based Learning Student Assessment Instrument (TBL-SAI), was administered at the end of each course ${ }^{7}$. An eight question subset of the TBL-SAI is validated to measure student accountability in $\mathrm{TBL}^{8}$, and is used as a measurement of student accountability to the team. The difference between student grades on the individual and team RATs give an indication about the degree to which students are working together to determine the correct answers on the RAT.

Data were collected regarding team conflict, team satisfaction, team interdependence, and team cohesiveness through the required peer review administered twice each term-during week 3 and at the end of the term-using CATME SMARTER Teamwork ${ }^{6}$.

\section{Results and Discussion}

The results of the TBL-Student Assessment Instrument are shown in Table 1. The table includes the possible range and the neutral point of the accountability subset. The range, average and standard deviation is given, as well as the percentage of the student's whose score was above the neutral point. The results indicate that $93 \%$ of the students felt accountable to not only themselves, but also to their team to participate in the learning.

Table 1: Results of TBL-SAI Accountability subset, which measures whether students felt accountable in the course

\begin{tabular}{|c|r|r|r|r|r|r|r|}
\hline $\begin{array}{c}\text { Possible } \\
\text { Range }\end{array}$ & $\begin{array}{c}\text { Minimum } \\
\text { Score }\end{array}$ & $\begin{array}{c}\text { Maximum } \\
\text { Score }\end{array}$ & $\begin{array}{c}\text { Neutral } \\
\text { Point }\end{array}$ & Average & $\begin{array}{c}\text { Standard } \\
\text { Deviation }\end{array}$ & $\begin{array}{c}\text { Percent } \\
\text { above } \\
\text { Neutral } \\
\text { Point }\end{array}$ & $\begin{array}{c}\text { Number of } \\
\text { Responses }\end{array}$ \\
\hline 8 to 40 & 17 & 40 & 24 & 30.5 & 4.25 & $92.7 \%$ & 150 \\
\hline
\end{tabular}

The peer evaluation results from the CATME peer evaluation regarding team conflict, team satisfaction, and team interdependence-shown in Tables 2,3 and 4-did not change from the first peer review to the final peer review. The minimum, maximum, average, standard deviation and t-value are listed for each category.

The teams exhibited rare to no team conflict-mean score 1.4/5 on the peer evaluation. In every category of team conflict the teams reported little or no conflict. Seven teams reported rare (greater than 2) task conflict both in week three, and at the end of the term. The task conflict 
questions asked about conflict of ideas and disagreements about the task. Only one team was rated having a total conflict of greater than 2 during week three and no teams were rated greater than 2 at the end of the term for total team conflict. Overall there was not a significant change in the reported team conflict in week three-which was already low-to the end of the term. The manner in which teams work on tasks during class in TBL creates an environment in which team members have little conflict.

Table 2: Results from Team Conflict evaluation. Scale: $1=$ None or Not at all, 2 = Little or Rarely, 3 = Some, $4=$ Much or Often, 5 = Very Much or Very Often

\begin{tabular}{|c|c|c|c|c|c|c|c|c|}
\hline & \multicolumn{2}{|c|}{ Relationship } & \multicolumn{2}{|c|}{ Task } & \multicolumn{2}{|c|}{ Process } & \multicolumn{2}{|c|}{ Total } \\
\hline & $\begin{array}{c}\text { Week } \\
3\end{array}$ & $\begin{array}{l}\text { End of } \\
\text { Term }\end{array}$ & $\begin{array}{c}\text { Week } \\
3\end{array}$ & $\begin{array}{l}\text { End of } \\
\text { Term }\end{array}$ & $\begin{array}{c}\text { Week } \\
3\end{array}$ & $\begin{array}{c}\text { End of } \\
\text { Term }\end{array}$ & $\begin{array}{c}\text { Week } \\
3\end{array}$ & $\begin{array}{l}\text { End of } \\
\text { Term }\end{array}$ \\
\hline Minimum & 1 & 1 & 1.4 & 1.33 & 1 & 1 & 1.16 & 1.16 \\
\hline Maximum & 1.8 & 1.94 & 2.6 & 2.73 & 1.67 & 1.67 & 2.02 & 1.91 \\
\hline Mean & 1.13 & 1.15 & 1.86 & 1.91 & 1.20 & 1.23 & 1.39 & 1.43 \\
\hline $\begin{array}{c}\text { Standard } \\
\text { Deviation }\end{array}$ & 0.19 & 0.22 & 0.30 & 0.37 & 0.16 & 0.19 & 0.19 & 0.21 \\
\hline Significance & \multicolumn{8}{|c|}{ NULL $\mathrm{p}=0.05$} \\
\hline t-value & \multicolumn{2}{|c|}{0.362} & \multicolumn{2}{|c|}{0.487} & \multicolumn{2}{|c|}{0.692} & \multicolumn{2}{|c|}{0.600} \\
\hline
\end{tabular}

Students were very satisfied with their teams-shown in Table 3-at week three and at the end of the term. There was no significant difference from the beginning to the end of the course. The teams did range in degrees of team satisfaction, especially at week three, which is expected as the teams learn to work together.

Table 3: Team Satisfaction. Questions asked on the scale: $1=$ Strongly Disagree, $2=$ Disagree, 3 = Neither Agree Nor Disagree, $4=$ Agree, $5=$ Strongly Agree

\begin{tabular}{|l|r|r|}
\hline & Week 3 & $\begin{array}{c}\text { End of } \\
\text { Term }\end{array}$ \\
\hline Minimum & 3.11 & 3.78 \\
\hline Maximum & 5 & 4.87 \\
\hline Mean & $\mathbf{4 . 4 1}$ & $\mathbf{4 . 5 3}$ \\
\hline Standard Deviation & 0.42 & 0.30 \\
\hline Significance & \multicolumn{2}{|c|}{ NULL p=0.05 } \\
\hline t-value & \multicolumn{2}{|c|}{1.386} \\
\hline
\end{tabular}

Team interdependence measures whether the individual members had to depend on each other in order to complete the work, including checking in with others, and asking advice. The teams had moderate team interdependence-shown in Table 4-and no significant change from week three to the end of the term. The amount of team interdependence depends on the type of problems given during the applications-whether the problems are large and difficult enough that the team has to work together to solve the problem and finish the application in the given time frame. 
Table 4: Team Interdependence. Questions asked on the scale: 1 = Strongly Disagree, 2 = Disagree, 3 = Neither Agree Nor Disagree, 4 = Agree, 5 = Strongly Agree

\begin{tabular}{|l|r|r|}
\cline { 2 - 3 } \multicolumn{1}{c|}{} & Week 3 & $\begin{array}{c}\text { End of } \\
\text { Term }\end{array}$ \\
\hline Minimum & 3.07 & 3.17 \\
\hline Maximum & 4.08 & 4.2 \\
\hline Mean & 3.58 & 3.59 \\
\hline Standard Deviation & 0.31 & 0.31 \\
\hline Significance & \multicolumn{2}{|c|}{ NULL p=0.05 } \\
\hline t-value & \multicolumn{2}{|c|}{0.140} \\
\hline
\end{tabular}

At three weeks into the term, the teams already exhibited cohesiveness, and the team cohesiveness had significant $(\mathrm{p}=0.06, \mathrm{t}=2.28)$ improvement at the end of the term in all categories except task attraction. It is expected that by the end of the term (or a project) teams will become cohesive and be able to effectively work together. The structure of TBL is such that teams already become cohesive after three weeks of working together-and meeting only three hours a week. The in-class activities are designed to maximize teams needing to work together to finish the task, and the students report that they need to work together-both through the quantitative questions and the comments from the students, discussed below.

Table 5: Team Cohesiveness. Questions asked on the scale: $1=$ Strongly Disagree, 2 = Disagree, 3 = Neither Agree Nor Disagree, 4 = Agree, 5 = Strongly Agree

\begin{tabular}{|c|c|c|c|c|c|c|c|c|}
\hline & \multicolumn{2}{|c|}{$\begin{array}{l}\text { Interpersonal } \\
\text { Cohesiveness }\end{array}$} & \multicolumn{2}{|c|}{$\begin{array}{c}\text { Task } \\
\text { Commitment }\end{array}$} & \multicolumn{2}{|c|}{$\begin{array}{c}\text { Task } \\
\text { Attraction }\end{array}$} & \multicolumn{2}{|c|}{ Total } \\
\hline & $\begin{array}{c}\text { Week } \\
3 \\
\end{array}$ & $\begin{array}{c}\text { End of } \\
\text { Term }\end{array}$ & $\begin{array}{c}\text { Week } \\
3 \\
\end{array}$ & $\begin{array}{c}\text { End of } \\
\text { Term }\end{array}$ & $\begin{array}{c}\text { Week } \\
3 \\
\end{array}$ & $\begin{array}{c}\text { End of } \\
\text { Term }\end{array}$ & $\begin{array}{c}\text { Week } \\
3 \\
\end{array}$ & $\begin{array}{c}\text { End of } \\
\text { Term }\end{array}$ \\
\hline Minimum & 3.40 & 3.44 & 3.25 & 4.00 & 3.20 & 3.06 & 3.50 & 3.65 \\
\hline Maximum & 4.89 & 4.67 & 4.89 & 4.67 & 4.56 & 4.33 & 4.78 & 4.53 \\
\hline Mean & 4.09 & 4.29 & 4.22 & 4.40 & 3.81 & 3.96 & 4.04 & 4.22 \\
\hline $\begin{array}{l}\text { Standard } \\
\text { Deviation }\end{array}$ & 0.31 & 0.28 & 0.37 & 0.18 & 0.37 & 0.28 & 0.30 & 0.20 \\
\hline Significance & \multicolumn{2}{|c|}{$\begin{array}{c}\text { significant at } \\
p=0.05\end{array}$} & \multicolumn{2}{|c|}{$\begin{array}{c}\text { significant at } \\
\mathrm{p}=0.05\end{array}$} & \multicolumn{2}{|c|}{ NULL $\mathrm{p}=0.05$} & \multicolumn{2}{|c|}{$\begin{array}{c}\text { significant at } \\
\mathrm{p}=0.05\end{array}$} \\
\hline t-value & \multicolumn{2}{|c|}{2.114} & \multicolumn{2}{|c|}{2.068} & \multicolumn{2}{|c|}{1.495} & \multicolumn{2}{|c|}{2.286} \\
\hline
\end{tabular}

To quantitatively measure team interdependence during the tRAT, the team tRAT score is compared to the team's average iRAT score and the range of the individual iRAT scores in Figure 2. Immediately evident from the plot is that the iRAT scores do not correlate to the team tRAT score. All teams, except one, had an average tRAT score of $90 \%$ or higher, regardless of the iRAT score. In addition, the average difference between the iRAT and tRAT scores is significant $(\mathrm{p}=0.0001, \mathrm{t}=16.4)$-an increase of 1.7 points-almost 2 grade points. The average difference between the top student in a team and the team score (0.82 points) is also significant $(\mathrm{p}=0.0001, \mathrm{t}=7.21)$. The conclusion from Figure 2 and the analysis of the iRAT and tRAT scores is that the students must work together in order to achieve the higher tRAT scores. 


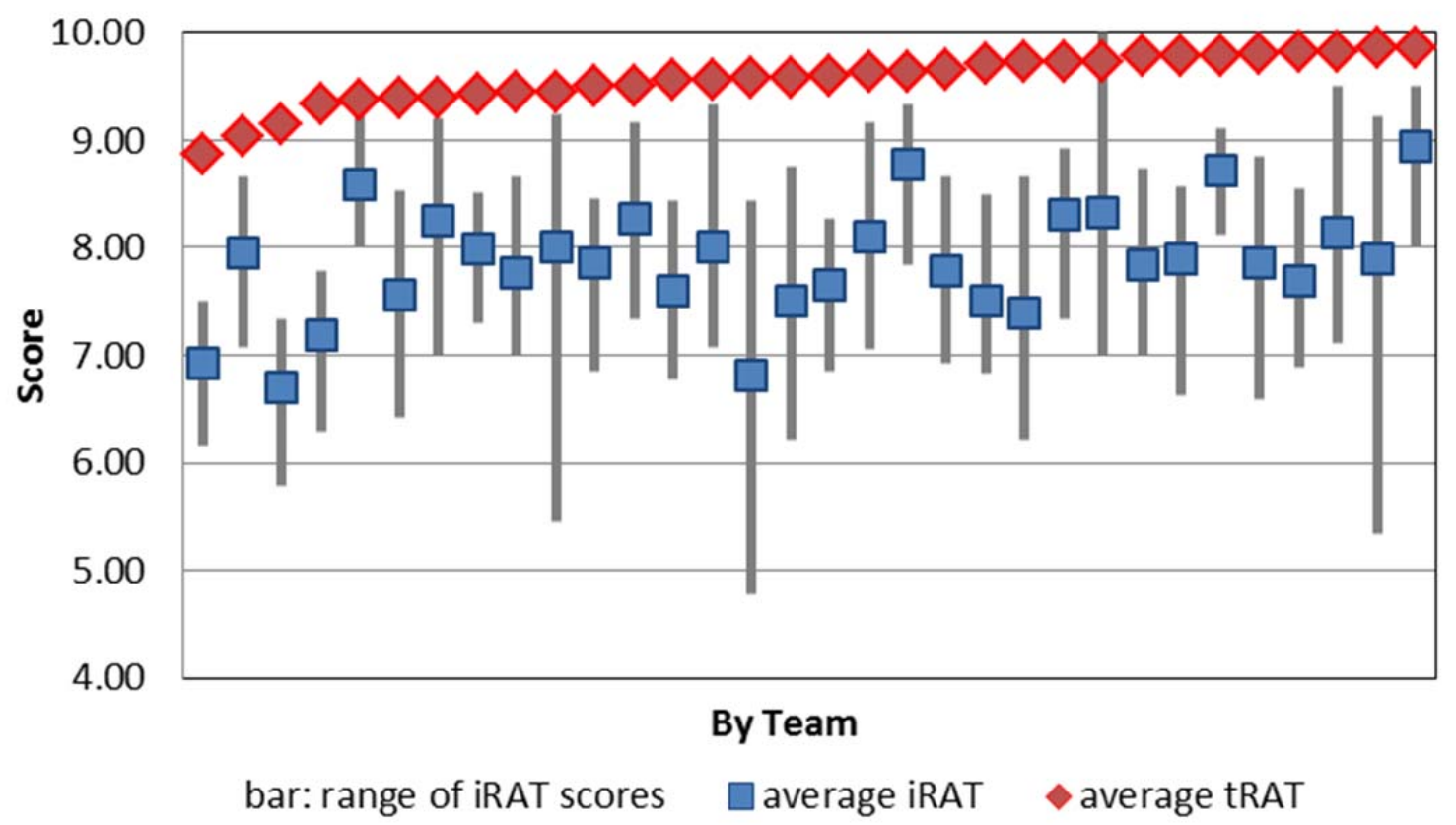

Figure 2: The differences between the top student and the team score and the average iRAT and the tRAT scores are significant. Students must work together as a team to achieve high tRAT scores. *Note: The one student who had an average of 10/10 on the iRAT was a graduate student.

To ensure individual accountability and encourage students to work together in the classroompracticing the skills they will need to know for the exams-the syllabus outlines that in order to pass the course, the student must pass the individually graded portion of the course, i.e., the iRAT, midterm and final exams. This policy not only ensures student accountability, but also informs the students that they will not be able to "slide by" on the team grade, and must take ownership of learning the material. If students were sliding by in-class, we would expect the failure rate to increase compared to a lecture only course, however, the failure rate is not significantly different. As Table 6 shows, students are not failing fundamental courses in the thermal sciences at a higher rate when using Team-Based Learning (one term comparison).

Table 6: Comparison of the failure rate in TBL taught courses and lecture taught courses.

\begin{tabular}{|c|c|c|}
\hline Course & TBL & Lecture \\
\hline Heat Transfer & $1.7 \%(n=58)$ & $2.7 \%(n=36)$ \\
\hline Thermodynamics 1 & $4.7 \%(n=63)$ & $5.7 \%(n=70)$ \\
\hline
\end{tabular}

In addition to the quantitative questions on the CATME peer review survey, the students have an opportunity to write comments about their team and team mates if they wish at the end of the survey. At week three there were 159 comments written by the students. Most of the comments (67\%) were positive about the team experience, and the students commented on the team interdependence and cohesiveness they noticed already at week three. Selected comments from the week three peer review are listed below. At three weeks in the term, the students recognize 
the power of the teams to work together to solve the problems and that the heterogeneity of the teams is helpful to the team.

Honestly the best team I have ever worked with in school.

Everyone contributes and pertinent information is provided by each [person].

There are some individuals in the group that are very confident with their answers and therefore [it] brings up a debate where we can constructively decide on the correct answer.

Whenever I don't get anything, someone will always be there to help explain.

I feel that we all put our heads together equally to solve applications, which is great because I don't feel like I'm less smart.

We've been able to be successful so far because we listen when we have differing opinions about questions and are able to resolve those opinions logically to find the correct answer.

Everyone comes to class having read the material and prepared to provide input.

All five of us are very different, but we each have something to offer that is valuable to the team.

It helps a lot to discuss the tricky questions with my team members, and I usually find that there is one clear answer.

Only $11 \%$ of the comments at week three were negative about their team, and most discussed what their team could do to improve. The remainder of the comments addressed the class structure in general. There were six teams in which students were specifically named in comments. Some team members were frustrated with the lack of preparation or attendance by a particular student. Even though some students did not attend class as much, it did not harm the team's function for those who did attend class. The format of TBL-such that the teams only meet in-class and work on problems-allows for students to work together and participate in the learning in-class, even if one team mate is not present.

The large teams in TBL are also important for the teams when one member is not as active as the other team members. When teams have six students, a team of five students is not at a disadvantage as much as a team of three or four that is missing a team mate. In the thermodynamics course, one team was reduced to four students as a result of students dropping the course. The students in this team recognized that the other teams were at an advantage when doing the in-class activities because there were more people with which to discuss ideas. At their request, this particular team was disbanded during week three, and the members were incorporated into the other teams. The comments at the end of the term confirm that being part of the larger teams enhanced their team experience and was a better fit than the four-person team. 
There were 124 comments from students from the end of term peer review. Again, most (87\%) of the comments were positive toward their team and the team experience. Some students commented that their teams had gotten better over the term. One of the purposes of doing the peer evaluation twice during the term is to give the students a chance to receive feedback on how they are doing and to be able to change their behavior before the end of the term. The final peer review counts toward each student's team grade. The interactive nature of the tRAT and immediate feedback encourages quieter students to speak up and gives students confidence in their understanding of the material and ability to contribute positively to the team.

This was honestly the best group I have ever worked with. I gave everyone high scores because they deserved those scores. It was a pleasure working with all of them.

This was my first time taking a team-based course and I can say that I enjoyed it for I gained a better understanding of the material due to experiencing several points of view while working through the problems together.

I like the team and I like the team environment. I feel much more confident tackling in-class applications when I have a team to help me through the problem and sometimes I get to help them and it feels good!

I think our team is pretty solid. We had a lot of different ideas, but were able to talk through them to pick the best one.

I am inherently less talkative than the rest of them I would say but that helped get me involved as well.

We have grown more cohesive over the quarter.

Throughout the quarter I think our group has really worked well together. I feel as though each member has made positive contributions from time to time. Some members seem to think quicker which enables them to figure out the problem faster, but by the end of the question each member takes the time to make sure all members have caught up and understand what is going on.

Everyone really stepped up their contribution to the tasks at hand. Our group applications and team tests were much more verbal and everyone did what they could to help out.

We all have our strengths and weaknesses and each of us had a say in the tRATS.

We each were able to discuss openly our opinions and respected each other.

The $8 \%$ of the comments that were negative came from four teams-out of a total of 32 teamswho had issues with one team mate not coming to class and/or not coming prepared and not 
participating. These students were also rated lower by their team mates in the quantitative section of the peer review and as a result, their adjustments scores were significantly less than 1, which reduced their personal team grade. Another purpose of the peer review at the end of the term is to incorporate individual accountability into the team activities. Team members who are not participating in the team are penalized in the peer review and their personal team grade is reduced. The student comments and their evaluation of their team mates match, and students are not allowed to "slide by" on their team mates' work. Exam scores of these students reflect their lack of participation in the team activities and are lower than their team mates' scores.

Instructor intervention was minimal in all courses. As discussed above the instructor only intervened one time to redistribute a team because the size of the team was too small, not because of any personality or working conflicts. In general, the instructor does not directly help the teams work together, and the instructor was not asked to intervene in any team disagreements by the teams. The teams-as a result of the TBL structure-are self-regulating.

\section{Conclusions}

Teams in Team-Based Learning courses learn quickly how to effectively work together. The teams exhibited rare to no team conflict. Seven teams-out of 22-surveyed in two fundamental mechanical engineering courses reported rare task conflict in both week three and at the end of the term. Overall there was not a significant change in the reported team conflict in week threewhich was already low-to the end of the term. The manner in which teams work on tasks during class in TBL creates an environment in which team members have little conflict.

Overall, students were very satisfied with their teams. Teams did range in degrees of team satisfaction at week three from 3.11 to 5 (Likert scale 1-5), but the range of satisfaction was narrower by the end of the term and ranged from 3.78-4.78, as a result of teams learning to work together over the term.

At three weeks into the term, the teams already exhibited cohesiveness, and the team cohesiveness had significant $(\mathrm{p}=0.06, \mathrm{t}=2.28)$ improvement at the end of the term in all categories except task attraction. The structure of TBL is such that teams already become cohesive after three weeks of working together-and meeting only three hours a week in-class.

Analyzing the data from 32 teams showed that the average difference between the individual (iRAT) and team (tRAT) scores was significant ( $\mathrm{p}=0.0001, \mathrm{t}=16.4)$. The average difference between the top student in a team and the team score was also significant $(\mathrm{p}=0.0001, \mathrm{t}=7.21)$. This shows that students worked together and cannot depend on the "smartest" student in the team in order to achieve the high tRAT scores. Therefore the teams were high functioning.

Student comments were overwhelming positive about the team experience and that the teams were working well together to solve the problems presented in class.

The TBL framework promotes high functioning, cohesive teams who do not depend on the strongest or smartest students, which results in an improved learning experience for all students. 
In addition, teams are self-regulating resulting in minimal guidance and intervention by the instructor. In order to achieve the high functioning teams, the course must have the following characteristics-heterogeneous, permanent teams, individual and team accountability, peer review and follow the TBL framework of readiness assurance process and then applications. TBL is therefore a prime candidate to be considered by instructors considering flipping an engineering course.

\section{References}

1. Sibley, J., \& Parmelee, D. (2008). Knowledge is no longer enough: Enhancing professional education with teambased learning. New Directions for Teaching and Learning, 2008(116), 41-53.

2. Michaelsen, L., \& Sweet, M. (2008). The essential elements of team-based learning. New Directions for Teaching and Learning, 2008(116), 7-27.

3. Sibley, J. (2014). Getting Started with Team-Based Learning. Sterling, Virginia: Stylus Publishing.

4. Layton, R. A., Loughry, M. L., Ohland, M. W., \& Ricco, G. D. (2010). Design and validation of a web-based system for assigning members to teams using instructor-specified criteria. Advances in Engineering Education, 2 (1), 1-28.

5. Ohland, M. W., Loughry, M. L., Woehr, D. J., Finelli, C. J., Bullard, L. G., Felder, R. M., Layton, R. A., Pomeranz, H. R., \& Schmucker, D. G. (2012). The comprehensive assessment of team member effectiveness: Development of a behaviorally anchored rating scale for self and peer evaluation. Academy of Management Learning \& Education, 11 (4), 609-630.

6. Loughry, M. L., Ohland, M. W., \& Moore, D. D. (2007). Development of a theory-based assessment of team member effectiveness. Educational and Psychological Measurement, 67, 505-524.

7. Mennenga, H. (2012). Development and psychometric testing of the team-based learning student assessment instrument. Nurse Educator, 37(4), 168-172.

8. Mennenga, H. (2010). Team-based Learning: Engagement and Accountability with Psychometric Analysis of a New Instrument. n.p.: ProQuest, UMI Dissertations Publishing 